\title{
Glycosyl ureides in ruminant nutrition
}

\section{Preparation and estimation of lactosyl urea and other glycosyl ureides}

\author{
BY R. J. MERRY, R. H. SMITH AND A. B. MCALLAN \\ National Institute for Research in Dairying, Shinfield, Reading RG2 9AT
}

(Received 27 July 1981 - Accepted 27 January 1982)

1. Glucosyl urea, lactosyl urea and galactosyl urea were prepared from pure sugars and urea and their purity confirmed by determination of their melting points, specific rotations and by mass spectrometry.

2. Using whey as a lactose source, a range of conditions were examined for the preparation of lactosyl urea on a laboratory scale. Yields of $60 \%$ were achieved when lactose and urea (molar ratio, urea:lactose $0: 6$ ) were reacted for $15 \mathrm{~h}$ in sulphuric acid at $\mathrm{pH} 2.0$ and a temperature of $70^{\circ}$.

3. Methods of detection and estimation of all three ureides in whey preparations and ruminant digesta samples were developed. Two quantitative methods, one involving acid-hydrolysis, the other ion-exchange chromatography, were used. The latter method enabled determination of individual quantities of ureides in mixtures.

The problems associated with the feeding of non-protein-nitrogen (NPN) are well documented (Chalupa \& Davis, 1976; National Academy of Sciences, 1976; Bartley \& Deyoe, 1977). The value of these compounds in practice may be limited in part by their potential toxicity and by the efficiency with which they are converted to microbial protein.

Attempts to improve on urea as an NPN source have generally been aimed at simply reducing the rate of ammonia release (Bartley \& Deyoe, 1977). This reduces the chance of accidental toxic effects but there is little or no evidence to indicate that it improves the efficiency of microbial protein synthesis (Smith et al. 1977; Smith, 1979). On the other hand there is evidence to suggest that rapidly-fermented energy sources such as soluble sugars are used less efficiently for microbial synthesis in the rumen than more slowly and steadily fermented starches (Al Attar et al. 1976; Bartley \& Deyoe, 1977; Oldham et al. 1977).

The glycosyl ureides (Goodman, 1958) are compounds which have received some attention as possible ruminant feed supplements, mainly because ammonia is released from them more slowly than from urea (Milligan et al. 1972; Galyamin, 1975). Nevertheless, it seems probable that their sugar component is also metabolized more slowly than would be the sugar in the free form. It appeared likely therefore that glycosyl ureides may combine low toxicity with a greater potential value for microbial protein synthesis, than their individual components. In practical terms, the possibility of making use of lactose in whey, a product often produced in surplus (Schingoethe, 1976; Balch \& Porter, 1977; Thivend, 1977), is of particular interest. It was apparent that further research was needed to make a proper assessment of the feeding value of these compounds and their practical use.

The present work was done to develop suitable preparative techniques and methods of detection and estimation of glycosyl ureides, particularly in relation to the use of whey as a starting material. Part of this work has been briefly reported earlier (McAllan et al. 1975).

\section{METHODS}

Paper chromatography of ureides and sugars was carried out by a method based on that of Benn \& Jones, (1960). Between 25 and $50 \mu$ l of the appropriately diluted samples, or standard aqueous solutions of pure glucosyl urea $(\mathrm{GU})$, lactosyl urea (LU), galactosyl urea $(\mathrm{Gal} \mathrm{U})$ or glucose, containing approximately $0.5 \mathrm{mg}$ of the compounds, were applied to 
Whatman no. 1 chromatography paper. Chromatograms were developed by descending irrigation for $72 \mathrm{~h}$. The solvent system employed was butan-1-ol: acetic acid: water $(4: 1: 5)$. Papers were air-dried and the spots detected by dipping into silver nitrate solution (Trevelyan et al. 1950), followed by further drying. Spots produced by unknown components were identified by comparison of values for the distance that spots had travelled, relative to that of glucose $\left(R_{\mathrm{G}}\right)$, with corresponding values for pure ureides.

Melting points were determined by observation of the temperature of decomposition of the unknown compound when heated in a capillary tube immersed in concentrated sulphuric acid. The specific rotation of a solution of a compound in water was determined using a polarimeter (no. 4138; C. P. Goerz, Berlin) with a path length of $0.2 \mathrm{~m}$.

Mass spectrometry was carried out on purified samples presumed to be GU, LU and Gal U. The compounds were silylated with bis(trimethylsilyl)trifluoroacetamide in pyridine (Gehrke \& Leimer, 1971) and low resolution mass spectra of the derivatives were recorded on an AEI MS902 mass spectrometer operated at 6 or $8 \mathrm{kV}$ with an ionization energy of $70 \mathrm{eV}$. Samples were introduced into the ion source using a direct insertion probe with the ion block heated to $190^{\circ}$.

Urea was estimated using an automated method based on the reaction between urea and diacetyl monoxime (2,3-butanedione-2-oxime) in the presence of thiosemicarbazide under acid conditions, to form a yellow-coloured product (Technicon Instruments Co. Ltd, 1967). Glucose was estimated enzymically by an automated glucose oxidase: peroxidase procedure (McAllan \& Smith, 1974). Ammonia was estimated by the method of Conway (1957) with boric acid in the central well and titration with $0.02 \mathrm{M}$-hydrochloric acid. Lactose, galactose and sometimes glucose were estimated using the method of Smith \& McAllan (1971).

\section{RESULTS}

\section{Preparation and characterization of pure ureides}

$G U$. A method based upon that of Hynd (1926) was used, but modified for larger-scale preparation. Equal weights $(1080 \mathrm{~g})$ of glucose and urea were dissolved in 51 distilled water. Sulphuric acid $(4.5 \mathrm{M} ; 224 \mathrm{ml})$ was then added with mixing. The solution was incubated at $50^{\circ}$ for $7 \mathrm{~d}$, with shaking twice daily. The resultant greenish-yellow liquid was concentrated to approximately $500 \mathrm{ml}$ under reduced pressure at $37^{\circ}$ using a rotary evaporator. Industrial methanol $(1.51)$ was added to the thin syrup obtained and the mixture kept at $4^{\circ}$ for $24 \mathrm{~h}$. In this time crystallization occurred. The crystals were separated through a filter paper on a Buchner funnel and washed by suspending them in 11 methanol and refiltering. Washing was repeated twice more. The crystals were dried in a vacuum desiccator and their melting point and specific rotation measured. Values obtained indicated that the crystals consisted of the urea adduct of 1-D-glucosyl urea (Hynd, 1926) (sample A, Table 1). This compound contained an additional molecule of urea bound to the GU molecule by weak hydrogen bonds which dissociated in solution.

The adduct $(280 \mathrm{~g})$ was converted to $\mathrm{GU}$ by refluxing with $100 \mathrm{ml}$ amounts of absolute ethanol for $4 \mathrm{~h}$. The ethanol was decanted off, replaced by a further $100 \mathrm{ml}$ and refluxing repeated. This procedure was repeated four more times. The resultant white crystals were washed once with absolute ethanol, dried, and examined for melting point and specific rotation. Values were similar to those reported for GU (sample B, Table 1). The mass spectrum obtained for the compound suspected to be GU showed no molecular ion $\left(\mathrm{M}^{+}\right)$ but a peak at $m / e 567$ was attributed to the pentasilylated derivative following the loss of a methyl group (M-15), which also indicated a molecular weight of 222 .

$L U$. Equal weights of lactose $(1080 \mathrm{~g})$ and urea were dissolved in 8.51 distilled water and $381 \mathrm{ml} 4.5 \mathrm{M}-\mathrm{H}_{2} \mathrm{SO}_{4}$ were added with mixing. Incubation conditions, methods of crystallization and washing were as described for the preparation of the urea adduct of GU, 
Table 1. Physical properties of some glycosyl ureides

(Each result was a mean of four readings)

\begin{tabular}{llcc}
\hline \hline Preparation examined & Melting point $\left(^{\circ}\right)$ & Identification \\
\hline & Literature values (Goodman, 1958) & \\
1-D-Glucosyl urea : urea & $171-172$ & $-18 \cdot 2$ & - \\
1-D-Glucosyl urea & $206-208$ & $-23 \cdot 5$ & - \\
$\beta$-D-Lactosyl urea & $230-240$ dec. & $+2 \cdot 1$ & - \\
1-D-Galactosyl urea & Amorphous & $+15 \cdot 0$ & \\
& \multicolumn{1}{c}{ Observed values } & \\
Sample A & $170-172 \quad$ & $-19 \cdot 6$ & 1-D-Glucosyl urea : urea \\
Sample B & $206-209$ dec. & $-24 \cdot 6$ & 1-D-Glucosyl urea \\
Sample C & $189-191$ & $+0 \cdot 8$ & Impure D-lactosyl urea \\
Sample D & $233-234$ dec. & $+2 \cdot 4$ & D-Lactosyl urea \\
Sample E & $232-233$ dec. & $+1 \cdot 6$ & D-Lactosyl urea \\
Sample F & $\simeq 192$ & $+12 \cdot 1$ & 1-D-Galactosyl urea \\
\hline \hline
\end{tabular}

* Specific rotation in water. dec., decomposed.

but drying of the product was carried out in a forced-draught oven at $37^{\circ}$ for $24 \mathrm{~h}$. No urea adduct was formed with lactose so the repeated refluxing with ethanol used in the preparation of GU was not required. The off-white crystals obtained after drying (sample $\mathrm{C}$, Table 1) were examined for melting point and specific rotation, but values were lower than those reported in the literature for LU, suggesting that impurities were present. The product was purified further by dissolving $500 \mathrm{~g}$ in approximately 31 hot distilled water on a steam bath. The hot solution was filtered on a pre-heated Buchner funnel. The filtrate was then cooled rapidly with shaking in an ice-bath and stored at $4^{\circ}$ for $16 \mathrm{~h}$. The finely-divided white crystals which formed were filtered off in a Buchner funnel and washed by suspending them in $1 \mathrm{l}$ ice-cold distilled water. The washing procedure was repeated twice and the crystals dried in a forced-draught oven at $37^{\circ}$ for $24 \mathrm{~h}$. The properties of the recrystallized product (sample D, Table 1) were similar to those reported for LU. The mass spectrum of the silylated compound presumed to be LU was obtained with an accelerating voltage of $6 \mathrm{kV}$ which increased the mass range to over 1000 . As with the glucose derivative, no molecular ion was found, but a peak at $m / e 945$ is consistent with octasilylation following the loss of a methyl group (M-15) from the molecular ion. This gave an estimated molecular weight of 384 , corresponding to that of $\mathrm{LU}$.

Gal $U$. Gal $U$ was prepared by the same method as for LU but on a smaller scale. Crystallization of the product from solution after addition of methanol was low and occurred over a period of approximately 3 months at $4^{\circ}$, but the crystals that formed (sample F, Table 1) appeared to be pure after washing with ice-cold distilled water and drying. The mass spectrum obtained from the silylated compound presumed to be Gal $\mathrm{U}$, was consistent with the molecule having been hexasilylated, with a molecular ion peak being present at $m / e 654$, giving an estimated molecular weight of 222, the same as that of Gal U.

\section{Preparation of $L U$ from unconcentrated whey}

Rennet-precipitated whey $(20 \mathrm{l})$ was stored at $-20^{\circ}$ in approximately $300 \mathrm{ml}$ batches. Lactose content $(49 \cdot 2 \mathrm{~g} / \mathrm{l})$ was estimated colorimetrically after anion-exchange chromatography (see p. 276). For one experiment, a thawed sample of whey was filtered and $250 \mathrm{ml}$ of the filtrate put into a $500 \mathrm{ml}$ conical flask. Sulphuric acid $(11.2 \mathrm{ml})$ of the appropriate concentration and $12.5 \mathrm{~g}$ of urea (equivalent by weight to the lactose present) were added 


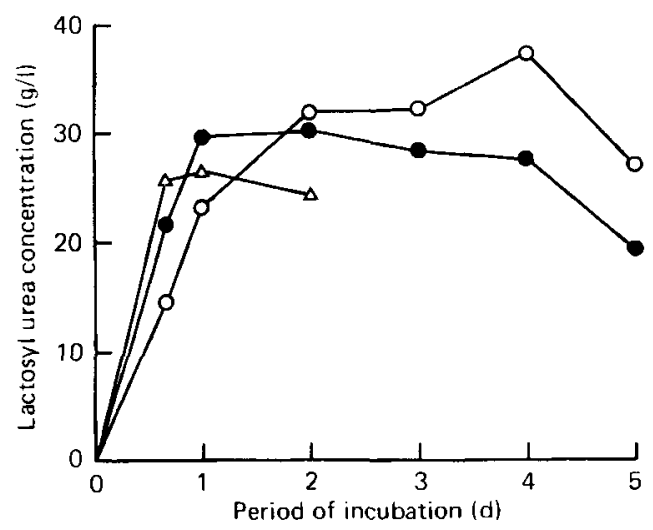

Fig. 1. Formation of lactosyl urea during reaction of lactose (in whey) with an equal weight of urea at $55^{\circ}$ with final sulphuric acid concentrations $(\mathrm{M})$ of $0.2(0), 0.4(-)$ and $0.5(\triangle)$.

and the flask covered and incubated in a shaking water-bath at the required temperature. At intervals, $30 \mathrm{ml}$ samples were withdrawn, neutralized with sodium hydroxide and ultrafiltered (Gregory, 1954) through Visking tubing (Union Carbide Co. Ltd, London) at $4^{\circ}$ for $16 \mathrm{~h}$. The ultrafiltrates were analysed for LU and lactose by ion-exchange chromatography and sometimes ammonia.

To prepare enough $L U$ from whey to isolate and identify the compound, 21 whey were reacted with urea in $0.2 \mathrm{M}-\mathrm{H}_{2} \mathrm{SO}_{4}$ in a scaled-up version of the method described previously. The reaction mixture was filtered and the filtrate warmed to $40^{\circ}$ and then centrifuged at $1200 \mathrm{~g}$ for $10 \mathrm{~min}$ at $4^{\circ}$. The liquid layer was removed from underneath the layer of fat which had formed, by suction. The preparation was ultrafiltered (Gregory, 1954) and 11 ultrafiltrate concentrated using a rotary evaporator under reduced pressure at $37^{\circ}$, until a thin syrup was obtained. Industrial methanol $(150 \mathrm{ml})$ was added to the syrup and the mixture kept at $4^{\circ}$ for $24 \mathrm{~h}$ when crystallization occurred. Crystals were separated from the mother-liquor by filtration on a Buchner funnel and washed by suspending them in $200 \mathrm{ml}$ methanol and refiltering. Washing was repeated twice more and then recrystallization from distilled water was carried out. The resulting white crystals were dried in a vacuum desiccator. The purified sample was examined for melting point and specific rotation. Values obtained indicated that the crystals were LU (sample E, Table 1).

Further confirmation of the purity of the isolated compound was obtained using paper chromatography. Aqueous solutions ( $10 \mathrm{~g} / 1,25 \mu \mathrm{l}$ amounts) of pure LU, glucose and the LU prepared from whey were applied to chromatography paper and eluted as described on p. 275. The $R_{\mathrm{G}}$ value obtained for the isolated LU was similar to that of the pure LU standard.

Effect of reaction time. The mixture of whey and urea in $0.2 \mathrm{M}-\mathrm{H}_{2} \mathrm{SO}_{4}$ was incubated at $50^{\circ}$ for up to $6 \mathrm{~d}$. These conditions were essentially the same as those employed by Hynd (1926). LU concentrations of 27,30 and $30 \mathrm{~g} / 1$ were present in the reaction mixture after 2,4 and $6 \mathrm{~d}$ respectively of incubation. This corresponded to approximately $40 \%$ conversion of lactose to LU after $4 \mathrm{~d}$ with $90 \%$ of the final total yield of $L U$ being formed after $2 \mathrm{~d}$ of incubation. An equivalent decrease was observed in the amount of lactose in the reaction mixture.

Effect of $\mathrm{H}_{2} \mathrm{SO}_{4}$ concentration at $50^{\circ}$. In a similar experiment in which the $\mathrm{H}_{2} \mathrm{SO}_{4}$ concentration was raised by increments from 0.2 to $0.5 \mathrm{M}$, increases in acid concentration speeded the initial rate of formation of $\mathrm{LU}$ with amounts of lactose disappearing 


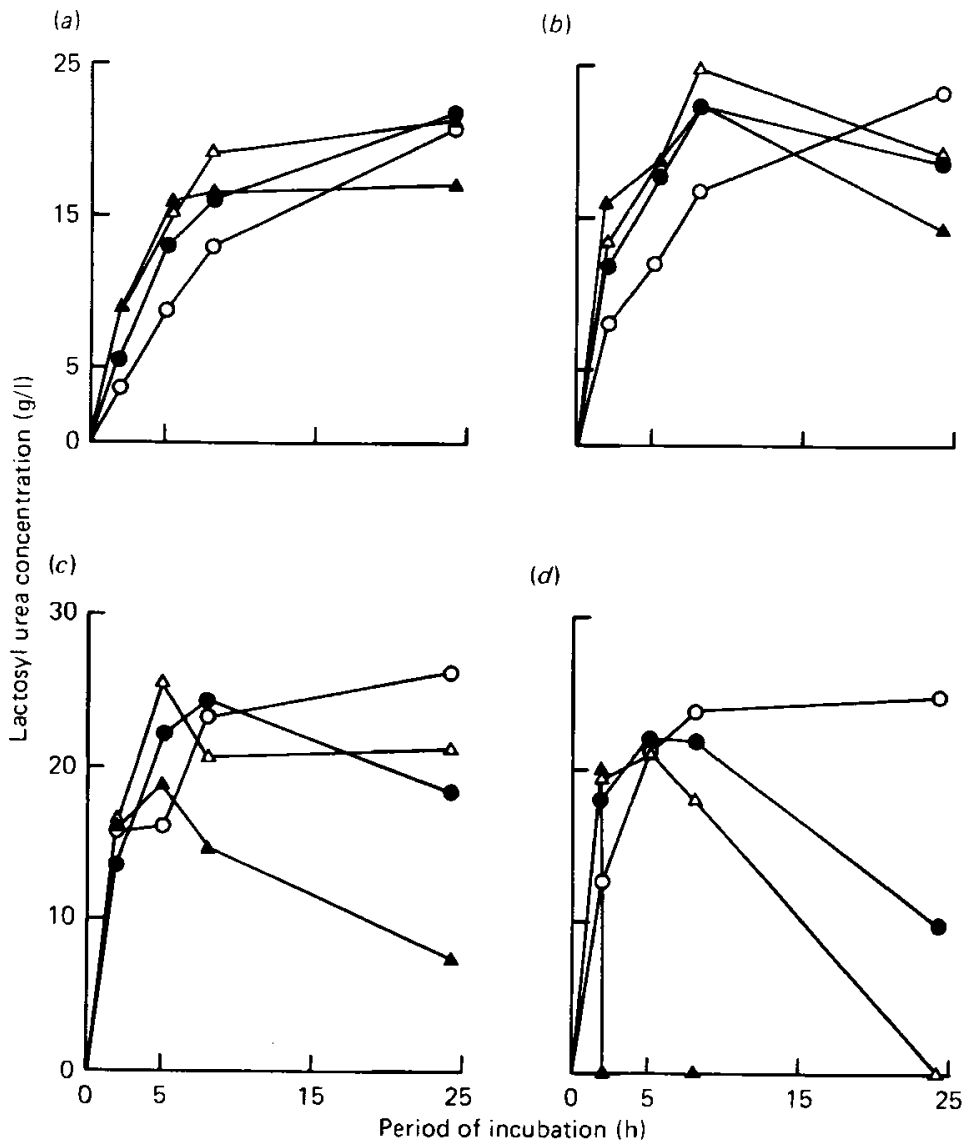

Fig. 2. Formation of lactosyl urea during reaction of lactose (in whey) with an equal weight of urea at (a) $55^{\circ},(b) 60^{\circ},(c) 65^{\circ},(d) 70^{\circ}$ and final sulphuric acid concentrations (M) of $0.25(\bigcirc), 0.5(\bigcirc), 0.75$ $(\triangle)$ and $1.0(\mathbf{\Delta})$.

approximately paralleling the $\mathrm{LU}$ formed. However, yields of $\mathrm{LU}$ tended to decrease at higher acid concentrations after approximately $24 \mathrm{~h}$ (Fig. 1), indicating that degradation of LU as well as synthesis was occurring. This was illustrated by the decrease in LU concentrations after $24 \mathrm{~h}$ which became apparent particularly at higher acid concentrations. Degradation of urea probably occurred, as ammonia- $\mathrm{N}$ was detected in the reaction mixture, but amounts represented less than $5 \%$ of the original urea present in the reaction mixture and were not greatly affected by increased acid concentration.

Effect of $\mathrm{H}_{2} \mathrm{SO}_{4}$ concentration at different temperatures. Previous experiments indicated that yields of LU did not increase greatly with reaction times of greater than $24-48 \mathrm{~h}$. Further experiments were carried out over 24-h periods using equal weights of urea and lactose, to define the optimum $\mathrm{H}_{2} \mathrm{SO}_{4}$ concentration, reaction temperature and time of reaction for a good yield of LU. All permutations of four acid concentrations $(0 \cdot 25,0.5$, 0.75 and $1.0 \mathrm{M})$ and four temperatures $\left(55,60,65\right.$ and $\left.70^{\circ}\right)$ were studied.

Although good yields of LU were obtained after only $8 \mathrm{~h}$ with the higher acid concentrations (Fig. 2), best yields (approximately $45 \%$ of maximum theoretical yield) were achieved with $0.25 \mathrm{M}-\mathrm{H}_{2} \mathrm{SO}_{4}$ at 65 or $70^{\circ}$ (Fig. $2 c, d$ ). Elevation of acid concentration led to more rapid formation of $\mathrm{LU}$ after $2-5 \mathrm{~h}$ of incubation, but this effect became less obvious 
(a)

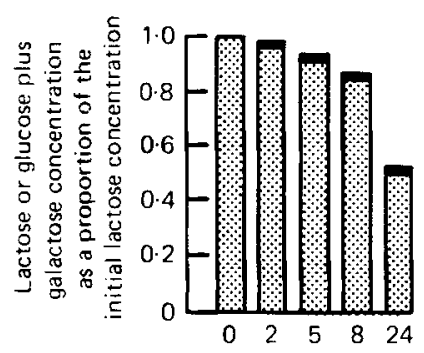

(b)

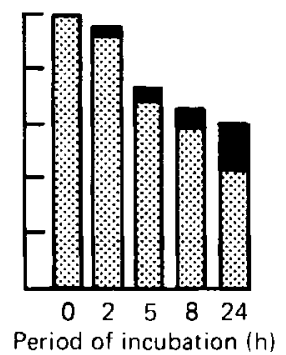

$(c)$

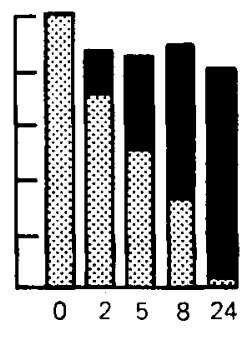

Fig. 3. Relative recoveries of glucose plus galactose released ( $\square$ ), and lactose remaining (䓒) (expressed as proportions of the original concentration), during incubation of lactose (in whey) with an equal weight of urea and $(a) 0.25 \mathrm{M}$-sulphuric acid at $55^{\circ},(b) 0.25 \mathrm{M}$-sulphuric acid at $70^{\circ},(c) 1.0 \mathrm{M}$-sulphuric acid at $70^{\circ}$.

as temperature increased and supported the previous observation that degradation was occurring. In these experiments the fate of lactose as well as the formation of $\mathrm{LU}$ was examined and some examples are shown in Fig. 3. At the lowest acid concentration and temperature $\left(0.25 \mathrm{M}\right.$ and $\left.55^{\circ}\right)$ little hydrolysis of lactose occurred. Nevertheless, with prolonged incubation, hydrolysis of lactose to produce glucose and galactose was marked, and increased with rise in temperature and acid concentration. Under the most extreme conditions of acid concentration and temperature $\left(1 \mathrm{M}\right.$ at $\left.70^{\circ}\right)$ almost complete degradation of lactose took place, and both synthesis and degradation of LU were almost certainly occurring simultaneously. Browning occurred in the incubation mixtures, as found by Lin \& Nickerson (1976) during acid-hydrolysis of lactose in whey, and was probably caused by caramelization and Maillard reactions with whey proteins.

It appeared that little advantage was achieved by increasing acid concentration above $0.25 \mathrm{M}$, but increases in temperature shortened the reaction time to between 8 and $24 \mathrm{~h}$, whilst maintaining a good yield of LU. Conditions adopted for further studies were $\mathrm{pH}$ 2.0 (approximately that achieved by a concentration of $0.25 \mathrm{M}-\mathrm{H}_{2} \mathrm{SO}_{4}$ in the mixture) at a temperature of $70^{\circ}$ for $16 \mathrm{~h}$.

Preparation of $L U$ from concentrated whey and permeate. Quantities $(5 \mathrm{~kg})$ of concentrated whey and permeate (supplied by the Milk Marketing Board, Thames Ditton), were deep frozen in batches of approximately $300 \mathrm{~g}$. Lactose concentrations in concentrated whey and permeate were 410 and $500 \mathrm{~g} / \mathrm{kg}$ wet material respectively. For an experiment, $300 \mathrm{~g}$ concentrate or permeate were placed in a $500 \mathrm{ml}$ conical flask. The appropriate amount of urea was added and the mixture acidified with $6 \mathrm{M}-\mathrm{H}_{2} \mathrm{SO}_{4}$ or $6 \mathrm{M}$-phosphoric acid, with mixing, to give the required $\mathrm{pH}$, and $40 \mathrm{~g}$ samples were weighed into $100 \mathrm{ml}$ glass flasks. The flasks were covered and incubated with shaking at 70 or $80^{\circ}$ for periods up to $24 \mathrm{~h}$. Flasks were removed at intervals, mixed well, and $5 \mathrm{~g}$ of the reaction mixture dissolved in $500 \mathrm{ml}$ distilled water. The diluted samples were ultrafiltered and LU and lactose estimated in the ultrafiltrate.

Effect of relative proportions of lactose and urea in the mixture and type of acid. Yields of $\mathrm{LU}$ for given amounts of concentrated whey after $15 \mathrm{~h}$ incubation at $\mathrm{pH} 2 \cdot 0$ (using $\mathrm{H}_{2} \mathrm{SO}_{4}$ as the acidifying agent), were highest when the molar ratio of urea:lactose in the reaction mixture was 5.7 (Table 2). With this value for the ratio, however, large amounts of urea remained unreacted. With lower values for the molar ratio of urea:lactose, the yields of LU, with concentrated whey and concentrated permeate were higher; when urea:lactose was 0.6 the proportion converted was $60 \%$. It appeared that under the conditions studied, 
Table 2. Yields of lactosyl urea (proportions of theoretical) during reaction of whey concentrate or whey permeate with urea in sulphuric acid or phosphoric acid at $70^{\circ}$ for 15 h at $\mathrm{pH} 2 \cdot 0$

\begin{tabular}{cccc}
\hline \hline Acid & $\begin{array}{c}\text { Molar ratio } \\
\text { (urea:lactose) }\end{array}$ & Whey concentrate & Whey permeate \\
\hline $\mathrm{H}_{2} \mathrm{SO}_{4}$ & 5.7 & 0.91 & $\mathrm{ND}$ \\
& 2.9 & 0.85 & $0 \cdot 81$ \\
& 1.4 & 0.60 & 0.63 \\
$\mathrm{H}_{3} \mathrm{PO}_{4}$ & 0.6 & 0.62 & 0.60 \\
& 0.6 & 0.53 & ND \\
\hline \hline
\end{tabular}

ND, not determined.

Table 3. Yields of lactosyl urea (proportions of theoretical) during reaction of whey concentrate with urea (molar ratio urea:lactose of 0.6 ) in sulphuric acid at $70^{\circ}$ or $80^{\circ}$ for $15 h$

\begin{tabular}{cccc}
\hline \hline $\mathrm{pH}$ & $70^{\circ}$ & $80^{\circ}$ \\
\hline 1.5 & 0.48 & 0.33 \\
2.0 & 0.48 & 0.45 \\
2.5 & 0.44 & 0.43 \\
3.0 & 0.32 & 0.40 \\
3.5 & 0.21 & 0.26 \\
4.0 & 0.13 & 0.18 \\
\hline
\end{tabular}

fairly good yields of LU would be obtained with a urea:lactose value of 1.0 and relatively small amounts of urea would remain unreacted.

In another experiment with concentrated whey where $\mathrm{pH}$ was adjusted to $2 \cdot 0$ using $\mathrm{H}_{3} \mathrm{PO}_{4}$, similar yields of LU were achieved to those obtained under identical conditions with $\mathrm{H}_{2} \mathrm{SO}_{4}$ (Table 2).

Effect of $\mathrm{pH}$ and temperature. In view of the potential problems of safety and corrosion at low $\mathrm{pH}$ under large-scale conditions, a study was made of the effect of $\mathrm{pH}$ on yield of LU.

Although even at $\mathrm{pH} 4.0$ and a temperature of $70^{\circ}$ some $\mathrm{LU}$ was formed, maximum yield of LU occurred at about $\mathrm{pH} 2.0$ (Table 3 ). When the temperature was raised to $80^{\circ}$ a similar overall picture was obtained but yield was depressed when the $\mathrm{pH}$ was below $2 \cdot 0$.

Determination of glycosyl ureides and sugars in whey products and biological fluids Acid-hydrolysis. It is known that GU is hydrolysed to glucose and urea under fairly stringent acid conditions (Schoorl, 1903). The possibility of using this reaction to estimate the ureides was investigated in the following experiments.

GU solutions $(2.5 \mathrm{~g} / 1 ; 2.5 \mathrm{ml})$ were diluted with equal volumes of $\mathrm{HCl}$ in Pyrex test-tubes $(150 \mathrm{~mm} \times 20 \mathrm{~mm})$ to give final acid concentrations of $0.4,0.6,0.8$ and $1.0 \mathrm{M}$. Cold-finger condensers were fitted and the mixtures refluxed. Tubes, in duplicate, were removed at intervals up to $3 \mathrm{~h}$ and cooled rapidly. Free urea and glucose were determined in the hydrolysates. Some of the results are shown in Fig. 4.

A similar experiment was made with a solution of $\mathrm{LU}(4.5 \mathrm{~g} / 1)$ in place of $\mathrm{GU}$, but with 


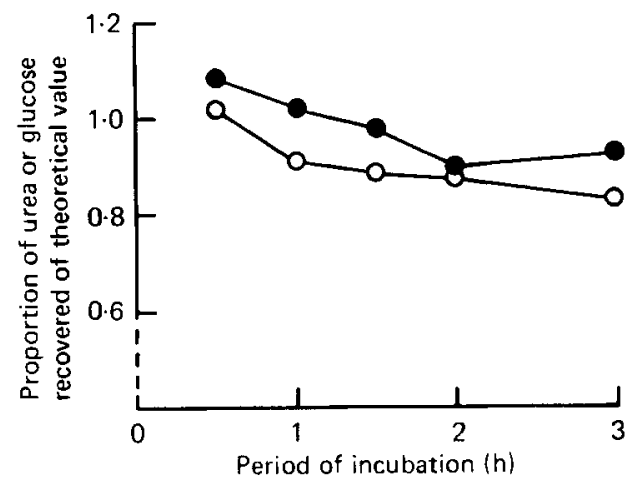

Fig. 4. Recoveries of urea $(O)$ or glucose $(\bigcirc)$ from glucosyl urea after hydrolysis at $100^{\circ}$ with $1 \cdot 0$ M-hydrochloric acid.

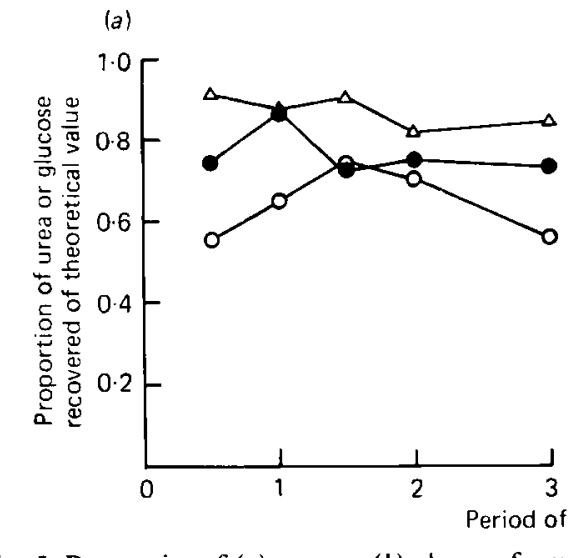

(b)

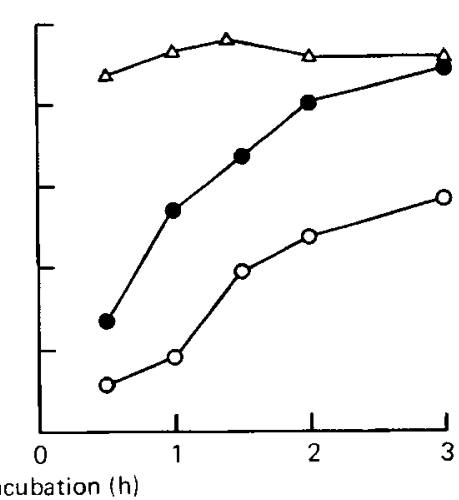

Fig. 5. Recoveries of (a) urea or $(b)$ glucose from lactosyl urea after hydrolysis at $100^{\circ}$ with $0 \cdot 2(O)$, $0.4(\bullet)$ and $1.0(\triangle)$ M-hydrochloric acid.

acid concentrations of $0 \cdot 2,0 \cdot 4,0 \cdot 6,0.8$ and $1 \cdot 0 \mathrm{M}$. Examples of some of the results are shown in Fig. 5 .

At acid concentrations of $0.6 \mathrm{M}$ and above, urea and sugar from $\mathrm{LU}$ and GU were recovered to extents of $90-95 \%$ after $1 \mathrm{~h}$. This is exemplified for $1.0 \mathrm{M}$ in Figs. 4 and 5 . Liberation of both urea and glucose from LU was slower at lower acid concentrations. It appeared that an incubation time of $1 \mathrm{~h}$ at an acid concentration of $0.6 \mathrm{M}$ would be most suitable for determining bound urea or sugars. Under these conditions recoveries (mean $\pm \mathrm{SE}$ ) of urea from LU and GU were $92.0 \pm 0.3$ and $100.8 \pm 0.3$ respectively for twelve determinations; corresponding recoveries of glucose were $92 \cdot 4 \pm 0 \cdot 3$ and $100 \cdot 3 \pm 0.4$ respectively.

The method was validated as follows. LU was added to rumen contents which had been strained through four layers of cheesecloth, to give a concentration of $2.8 \mathrm{mg} \mathrm{urea} / \mathrm{ml}$. The sample was acidified with $\mathrm{HCl}$ to give a final concentration of $0.6 \mathrm{M}$. A pure solution of $\mathrm{LU}$ of the same concentration to that in the samples was similarly acidified and included, to allow correction to be made for complete recovery of LU from rumen contents. Hydrolyses of samples and pure LU solutions were carried out as described previously and urea was estimated in the hydrolysates. Corrected recoveries were calculated in the following way $\mathrm{A} \times(\mathrm{B} / \mathrm{C})$ where: 


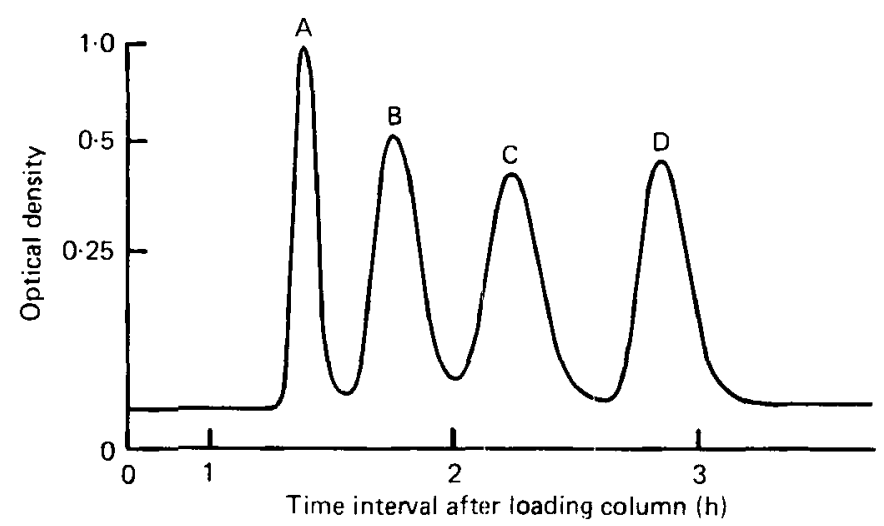

Fig. 6. Chromatogram of a mixture of pure glycosyl ureides and trehalose. Amounts of (A) glucosyl urea

(B) trehalose (C) lactosyl urea (D) galactosyl urea were respectively $140,125,140$ and $160 \mu \mathrm{g}$.

$A=$ Concentration of bound urea determined after hydrolysis of rumen contents with added LU.

$\mathrm{B}=$ Theoretical concentration of bound urea in the pure LU solution.

$\mathrm{C}=$ Concentration of LU determined in the pure LU solution.

Mean $( \pm \mathrm{SE})$ recovery of bound urea estimated in this way was $100 \cdot 8 \pm 1 \cdot 2$ for eleven samples.

Ion-exchange chromatography. In preliminary experiments borate complexes of mixtures of glycosyl ureides were prepared by adding boric acid. These compounds were separated on an anion-exchange resin as described by Smith \& McAllan (1971). The column effluent was mixed with $\mathrm{H}_{2} \mathrm{SO}_{4}$ and orcinol, and sugars detected by the yellow-coloured complex produced, using an autoanalytical technique (Smith \& McAllan, 1971). Mean ( \pm SE) sensitivities of lactose and LU to the procedure, relative to that of the internal standard 6-0- $\alpha$-D-glucopyranosyl-D-fructose (palatinose) (test sugar peak area:peak area for an equal weight of palatinose) were $1.41 \pm 0.03$ and $1.29 \pm 0.03$ respectively (twelve determinations).

This method was suitable for analysis of LU or GU present separately and for sugars mixed with those compounds, but did not resolve $\mathbf{L U}$ and GU. To separate these compounds and $\mathrm{Gal} \mathrm{U}$ a modified method was developed. A satisfactory resolution of these compounds and $\mathrm{Gal} \mathrm{U}$ was achieved by flushing the resin (after regeneration for $16 \mathrm{~h}$ with $0.33 \mathrm{M}$-potassium tetraborate) with $0.025 \mathrm{M}$-boric acid for $90 \mathrm{~min}$, before loading a sample to the column. Samples and standards were mixed, and diluted with boric acid buffer $(1.0 \mathrm{M}$, $\mathrm{pH} 7.0$ ) to give a final borate concentration of $0.025 \mathrm{M}$. The sample-standard mixture was loaded on to the column and eluted with $0.025 \mathrm{~m}$-boric acid. Correlation between peak area and quantity of sugar added to the column was reproducible and linear; however, an internal standard was required to allow for changes in the system with time.

Of several sugars investigated for this purpose, trehalose, which was eluted as a well-defined, symmetrical peak between those of LU and GU after approximately 100 min, was the most satisfactory. It was not detected as a natural constituent of samples requiring analysis. Relative sensitivities (test sugar peak area: peak area for an equal weight of trehalose) (mean $\pm \mathrm{SE}$ ), each for fifteen determinations, were $0.75 \pm 0.05,0.74 \pm 0.06$ and $0.57 \pm 0.03$ for $G \bar{U}, L U$ and Gal $U$ respectively. A typical chromatogram of a mixture of ureides and trehalose is shown in Fig. 6.

This method was tested using samples of sheep digesta to which known amounts of LU 
Table 4. Glycosyl ureide content $(\mathrm{g} / \mathrm{kg}$ dry matter) of products prepared from whey*

\begin{tabular}{|c|c|c|c|c|c|}
\hline & \multicolumn{5}{|c|}{ Batch no. } \\
\hline & 1 & 2 & 3 & 4 & 5 \\
\hline Lactosyl urea & $333 \cdot 9$ & $281 \cdot 0$ & $313 \cdot 4$ & $605 \cdot 5$ & $446 \cdot 3$ \\
\hline Glucosyl urea & $6 \cdot 6$ & 2.8 & $4 \cdot 8$ & $8 \cdot 1$ & $7 \cdot 2$ \\
\hline Galactosyl urea & $13 \cdot 3$ & $5 \cdot 0$ & $3 \cdot 2$ & $11 \cdot 3$ & $11 \cdot 3$ \\
\hline
\end{tabular}

* Commercially prepared by Ewos AB PO Box 618, S-15127 Södertälje, Sweden.

and GU had been added. Rumen or abomasal contents were centrifuged at $35000 \mathrm{~g}$ for $10 \mathrm{~min}$ and $\mathrm{LU}$ and GU were added to give concentrations of $100 \mu \mathrm{g} / \mathrm{ml}$. Samples were analysed as described previously. Recoveries (mean $\pm \mathrm{SE}$ ) of LU and GU from sheep rumen contents were $99 \cdot 27 \pm 2 \cdot 20$ and $97 \cdot 16 \pm 1 \cdot 13$ respectively. Recoveries of LU and GU from sheep abomasal contents were $97 \cdot 87 \pm 3 \cdot 87$ and $95 \cdot 33 \pm 2 \cdot 38$.

Analyses were also made of $L U$ and small amounts of GU and Gal $U$ in whey preparations. Examples of some results obtained are shown in Table 4.

\section{DISCUSSION}

A considerable amount of ureide is needed if studies are to be made of its metabolism in the ruminant animal. Early published methods for the preparation of glycosyl ureides (see Goodman, 1958) did not give much attention to obtaining high yields in short times and methods for quantitative estimation were not developed. Only very recently has a method been published with this intention (Gouda et al. 1980).

The two quantitative methods developed in the present work are useful for different purposes. The acid-hydrolysis procedure, suitable for rapid determination of bound urea and sugar, is of value for samples in which GU is the only ureide. It is, however, of limited use for mixtures of ureides as it does not distinguish between the different compounds (Merry, 1980). The ion-exchange chromatographic method, which allows individual quantification of $\mathrm{LU}, \mathrm{GU}$ and $\mathrm{Gal} \mathrm{U}$ is relatively time consuming but it is much less complex than the method of Gouda et al. (1980) which involves gas-liquid chromatographic analysis of derivatives of sugars before and after enzymic- and acid-hydrolysis of samples containing ureides.

Most methods reported for the preparation of glycosyl ureides are derived from the procedure developed by Schoorl (1903) which was subsequently modified by Hynd (1926). The methods are intended for small-scale laboratory preparation and generally provide low yields of materials and leave considerable amounts of uncombined urea in the crude reaction mixture. Cerbulis et al. (1978) have recently examined conditions for the preparation of LU on a laboratory scale. Their conclusions that a higher temperature with an initial $\mathrm{pH}$ value of 2.0 reduces the required reaction time, broadly agree with our findings. Like earlier workers these authors were mainly interested in preparing and characterizing pure reaction products and gave no detailed information on yields of LU.

Since the brief report of feeding experiments with GU by Milligan et al. (1972) there have been further reports of materials referred to as ureides being used in ruminant feeding. However, for a proper understanding of the metabolism of ureides by the ruminant it is essential that materials tested should be characterized in some such way as described previously. This has not been done and products alleged to contain ureides may not include such compounds. Thus for example, Galyamin (1975) used a product prepared from beet 
molasses and urea. The nature of the material formed was not clearly established and as sucrose does not form a ureide, presumably inversion of the sugar was necessary to release the individual monosaccharides before reaction with urea could have occurred. The value of the product, therefore, presumably lay in the formation of $\mathrm{GU}$, as fructose does not react with urea (Goodman, 1958). Demeyer \& Van Nevel (1978) tested a similar product and expressed doubt as to whether a ureide was present; their results suggested that the $\mathrm{N}$ of the urea in the product was not available to the rumen microbes.

That lactose is a sugar capable of forming a ureide (Schoorl, 1903) was confirmed in the present studies. Its presence in whey (approximately $700 \mathrm{~g} / \mathrm{kg}$ dry matter) means that a source exists for ureide formation that may be of economic importance. Whey is produced in considerable excess in many countries (Schingoethe, 1976; Balch \& Porter, 1977; Thivend, 1977) and often leads to disposal problems. The present studies point the way to procedures that may allow the conversion of this, often waste material, to potential ruminant feed.

For practical reasons (safety, vessel construction, etc.) less acid conditions would be desirable but yields of LU decreased markedly when the $\mathrm{pH}$ was raised from $2 \cdot 0$ to $4 \cdot 0$, even at fairly high temperatures. This agreed with the findings of Cerbulis et al. (1978) that the yield of LU decreased progressively as the $\mathrm{pH}$ increased above $3 \cdot 0$, and with no $\mathrm{LU}$ being formed at $\mathrm{pH} 7.0$ The present findings indicated that below $2 \cdot 0$, increased degradation of products more than offset an increased rate of synthesis. Degradation reactions included some conversion of lactose to glucose and galactose and formation of small amounts of GU and Gal U; a finding also reported by Cerbulis et al. (1978). For practical purposes it was necessary to strike a balance between moderate acid strength and a fairly high temperature, where good yields of LU could be achieved in a relatively short time. The reaction conditions suggested as being most suitable by the present study were a $\mathrm{pH}$ of $2 \cdot 0$ at a temperature of $70^{\circ}$ for $15 \mathrm{~h}$ which would lead to $50 \%$ conversion of equimolar amounts of lactose and urea to LU. These conditions have formed the basis of a pilot-plant process in Sweden (Widell, 1979).

In conclusion, it seems from the present investigation that a product could be formed by reacting whey and urea which may be a potentially useful feed supplement for ruminants.

The authors would like to thank Mr J. C. Price and Dr D. J. Manning for their valuable co-operation in carrying out mass spectrometric examination of some of the compounds prepared in the course of this work.

\section{REFERE NCES}

Al Attar, A., Evans, R. A. \& Axford, R.F.E. (1976). Proc. Nutr. Sac. 35, 108 A.

Balch, C. C. \& Porter, J. W. G. (1977). Symp. zool. Soc. Lond. no. 48, 285.

Bartley, E. E. \& Deyoe, C. W. (1977). In Recent Advances in Animal Nutrition, p. 50 [W. Haresign and D. Lewis, editors]. London: Butterworths.

Benn, M. H. \& Jones, A. S. (1960). J. chem. Soc. p. 3837.

Cerbulis, J., Pfeffer, P. E. \& Farrell, H. M. (1978). Carbohydr. Res. 65, 311.

Chalupa, W. \& Davis, R. F. (1976). Proc. Mld Nutr. Conf. Fd Mfrs, University of Maryland, p. 6.

Conway, E. J. (1957). Microdiffusion Analysis and Volumetric Error, 4th ed. London: Crosby Lockwood.

Demeyer, D. \& Van Nevel, C. (1978). Revue Agric. Brux. 31, 1094.

Galyamin, N. L. (1975). Zhivotnovodstvo. 9, 30.

Gehrke, C. W. \& Leimer, K. (1971). J. Chromat. 57, 219.

Goodman, I. (1958). Adv. Carbohydr. chem. 13, 215.

Gouda, I., Larm, O. \& Larsson, K. (1980). Swedish J. agric. Res. 10, 97.

Gregory, M. E. (1954). Br. J. Nutr. 8, 340.

Hynd, A. (1926). Biochem. J. 20, 205.

Lin, A. Y. \& Nickerson, T. A. (1976). J. Dairy Sci. 60, 34.

McAllan, A. B., Merry, R. J. \& Smith, R. H. (1975). Proc. Nutr. Soc. 34, 90A.

McAllan, A. B. \& Smith, R. H. (1974). Br. J. Nutr. 31, 77. 
Merry, R. J. (1980). The use of dietary non-protein nitrogen compounds by the ruminant with particular emphasis on the glycosyl ureides. PhD Thesis, University of Reading.

Milligan, L. P., Worsley, M., Elofson, M., Young, B. A. \& Atwal, A. S. (1972). J. Anim. Sci. 34, 89A.

National Academy of Sciences (1976). Urea and Other Non-protein Nitrogen Compounds in Animal Nutrition. Washington, DC: National Research Council.

Oldham, J. D., Buttery, P. J., Swan, J. \& Lewis, D. (1977). J. agric. Sci., Camb. 89, 467.

Schingoethe, D. J. (1976). J. Dairy Sci. 59, 556.

Schoorl, M. N. (1903). Recl. Trav. chim. Pays-Bas, 22, 31.

Smith, R. H. (1979). J. Anim. Sci. 49, 1604.

Smith, R. H. \& McAllan, A. B. (1971). Automation in Analytical Chemistry (Technicon International Symposium, 1969), p. 207. Basingstoke: Technicon Instruments Co. Ltd.

Smith, R. H., Salter, D. N. \& Daneshvar, K. (1977). J. Nuclear agric. Biol. 6, 8.

Technicon Instruments Co. Ltd (1967). Methodology sheet N-1c. New York: Technicon.

Thivend, P. (1977). Wld. Anim. Rev. 23, 20.

Trevelyan, W. E., Proctor, D. F. \& Harrison, J. S. (1950). Nature, Lond. 166, 444.

Widell, S. (1979). Proc. Whey Products Conf., Minneapolis, 1978, p. 53. Whey Products Institute and USDA. 